\title{
Influenza circulating viruses, positivity rate and risk factors for influenza associated severe acute respiratory infection during 2018/2019 winter season, Yemen
}

\author{
Mohammed Al Amad ${ }^{1 *}$ (1) and Khaled Almoayed ${ }^{2}$ (i)
}

\begin{abstract}
Background: The burden of seasonal influenza in conflict counties is exacerbated due to limited resource and collapse of health system. During 2018/2019 season, two-fold increase in the incidence of influenza was reported in Yemen with 22\% case fatality of severe acute respiratory infection (SARI). The aims are to analyze the influenza circulating viruses, positivity rate and risk factors for hospitalizing influenza associated-SARI.

Methodology: We used a retrospective analytical study based on surveillance data. All reported patients during 2018/2019 season, fulfilling the WHO cases definition for SARI or influenza like illness (ILI), and had laboratory result from the National Laboratory were included. Influenza positivity rate was calculated, all SARI and ILI patients with positive influenza were included for further analysis by univariate and multivariate binary logistic regression. Crude and adjusted Odds ratio (AOR), 95\% confidence interval and P-value $<0.05$ were used for statistically significant.

Results: Out of 2186 patients enrolled, 768 patients were tested for influenza viruses,: 19\% were children $<15$ years, $15 \%$ were $\geq 65$ years, $69 \%$ males and $18 \%$ had co-morbidity with chronic diseases. Patients with SARI were $37 \%$ and 63\% were ILI patients. Influenza viruses were detected in 411 (53.5\%), 68\% were influenza A subtype (H1N1)pdm09, $27 \%$ influenza B and $5 \%$ was influenza A not subtyped. The influenza positivity was significantly higher in SARI compared to ILI for patients $<15$ years ( $95 \% \mathrm{vs,} 66 \%, \mathrm{p}<0.001)$, and patients $\geq 65$ years ( $83 \% \mathrm{vs.} 56 \%, \mathrm{p}<0.002$ ), respectively. The highest positivity for influenza type $A$ and $B$ reached $44 \%$ and $33 \%$ for patients $\geq 65$ years and $<15$ years, respectively. The risk factors for influenza-associated SARI in multivariate analysis included age $<5$ [AOR 2.8] and $\geq 65$ years old [AOR 3.1] compared to age $5-<25$ years, diabetes [AOR 4.7], heart diseases [AOR 3.1] and chronic respiratory diseases [AOR 5.0].

Conclusion: The influenza positivity during 2018/2019 winter season was high in Yemen and varied by age distribution. Influenza subtype A (H1N1) pdm09 was the predominant and co circulated with influenza B. An influenza vaccination program for the risk group is necessary. Strengthening lab capacity to detect respiratory pathogens and further prospective study for more comprehensive picture are recommended.
\end{abstract}

Keywords: Influenza, Positivity rate, SARI, Risk factors, Yemen

*Correspondence: mohdalemad@yahoo.com

${ }^{1}$ Yemen Field Epidemiology Training Program, Sana'a, Yemen

Full list of author information is available at the end of the article

\section{Background}

Influenza is a respiratory diseases caused by influenza viruses. Type $\mathrm{A}$ and $\mathrm{B}$ are responsible for 3 to 5 million cases of severe acute respiratory infection (SARI) and

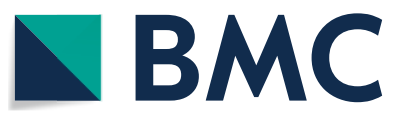

(c) The Author(s) 2022. Open Access This article is licensed under a Creative Commons Attribution 4.0 International License, which permits use, sharing, adaptation, distribution and reproduction in any medium or format, as long as you give appropriate credit to the original author(s) and the source, provide a link to the Creative Commons licence, and indicate if changes were made. The images or other third party material in this article are included in the article's Creative Commons licence, unless indicated otherwise in a credit line to the material. If material is not included in the article's Creative Commons licence and your intended use is not permitted by statutory regulation or exceeds the permitted use, you will need to obtain permission directly from the copyright holder. To view a copy of this licence, visit http://creativecommons.org/licenses/by/4.0/. The Creative Commons Public Domain Dedication waiver (http://creativeco mmons.org/publicdomain/zero/1.0/) applies to the data made available in this article, unless otherwise stated in a credit line to the data. 
290,000 to 650,000 deaths per year [1]. The severity of influenza viruses is mainly due to exacerbations of some underlying conditions or due to bacterial co-infection and secondary infection that synergize influenza viruses and leading to severe complication, e.g. respiratory distress syndrome (ARDS), respiratory failure and death [2-4]. The burden of SARI in conflict and crisis counties is high due to the limited access and collapse of health system [5]

Yemen has started SARI surveillance at the end of 2010 by establishing two sentinel sites; one site was in Sana'a city and one was in Aden city. During 2010 to 2016, many studies on SARI patients have shown influenza positivity rate between $5-10 \%$ and $10 \%$ case fatality rate [6-8].

The electronic disease early warning system (eDEWS), due to the war and limited access to health facilities has been strengthen to function as integrated system for all infectious disease since the end of 2016. It has covered all functional healthcare facilities and became the main source of data in the county [9-11]. Almost 7132 and 94,377 of SARI and ILI cases have been reported in 2017 [11]. Increase SARI during influenza season lead to overload hospitalization and admission to intensive care units [12]. The management of SARI patients in Yemen is challenging, only $49 \%$ of healthcare facilities are functioning and the majority of these healthcare facilities has shown to be poorly equipped to manage this type of infection [13-15]. During 2018/2019 season, two-fold increase in the incidence of influenza with $22 \%$ case fatality rate among influenza associated SARI has been reported by previous study [16].

Thus, interventional prevention against seasonal influenza such vaccination as recommended by World Health Organization (WHO) [17], could help to reduce SARI incidence, hospitalization and case fatality.

Identification the type of influenza viruses as well as risk factors for influenza hospitalization are the first steps for such intervention. The aims are to analyze the influenza circulating viruses, positivity rate and risk factors for hospitalizing influenza associated SARI.

\section{Methods}

\section{Study design}

A retrospective analytical study based on secondary data of influenza surveillance. All SARI and ILI patients with positive influenza result were included for further analysis for the risk factors of influenza associated-SARI.

\section{Study population}

All patients enrolled through ILI and SARI surveillance, with data collected by surveillance staff as a part of the epidemiological surveillance during 2018/2019 season
(November 2018-February 2018) and had laboratory test result for influenza viruses.

\section{Case definitions}

The surveillance team used WHO's case definitions for SARI and ILI. A SARI case defined as any patient presenting with acute respiratory infection, had a history of fever or measured fever of $\geq 38{ }^{\circ} \mathrm{C}$ within the previous 10 days and requiring hospitalization. An ILI case is defined as an outpatient presenting with acute respiratory infection including, history of fever or measured fever of $\geq 38{ }^{\circ} \mathrm{C}$ within the previous 10 days $[18,19]$.

\section{Study sites}

Public and private hospitals covered by influenza surveillance, located in cold climate governorates including; AL Amanah, Albydaa, Al Mhweet, Amran, Dhmar, Hajah, Ibb, Saada, Sana,a and Taiz governorates were included in this study.

\section{Data collection}

An investigation form was used for collecting data from adult patients or from parents in case of children. Demographic data; date of onset, clinical symptoms at admission such as history of fever or measured fever $\geq 38{ }^{\circ} \mathrm{C}$, cough onset within previous 10 days were collected. As well as comorbidities-chronic diseases such as diabetes, hypertension, heart disease, renal diseases, respiratory diseases; asthma, chronic pulmonary disease, TB and if the case was an ILI or SARI.

\section{Samples}

Nasopharyngeal $(\mathrm{N})$ and oropharyngeal $(\mathrm{O})$ swabs were collected immediately after the clinical examination. The samples were transported at $4{ }^{\circ} \mathrm{C}$ within $24 \mathrm{~h}$ to National Central public Health Laboratory $(\mathrm{NCPH})$ along with the investigation forms. At $\mathrm{NCPH}$ the primers and robes provided by $\mathrm{CDC}$ were used for detecting influenza $\mathrm{A}$ and $\mathrm{B}$ viruses by Reverse transcription Polymerase Chain Reaction (RT-PCR).

\section{Statistical analysis}

The data were analyzed by Epi Info version 7.2. Positivity rate for influenza was calculated by dividing the number of patients with positive influenza by total number of patients who had laboratory result for influenza. Chi-square test was used to test the differences of influenza positivity according to severity of infection and age group.

Univariate and multivariate binary logistic regression were used to calculate the crude and adjusted odds ratio, respectively with $95 \%$ Confidence Interval (CI). p 
value $<0.05$ was considered as the cut point for statistically significant.

\section{Result}

\section{Patient's characteristics}

From November 2018 to February 2019, 2186 patients from ten governorates enrolled in influenza surveillance including 652 (30\%) SARI cases and 1434 (70\%) ILI cases. From the total 2186 patients $768(35 \%)$ were tested for influenza viruses accounted for $43 \%$ (248 of 652) and 32\% (484 of 1534) of SARI and ILI cases, respectively. Of them $19 \%$, were children $<15$ years, $15 \%$ were $\geq 65$ years, $69 \%$ were males and $18 \%$ had underlying conditions; diabetes, heart diseases and renal diseases were among 10\%, $6 \%$ and $6 \%$ respectively, hypertension were among 5\% and respiratory diseases were among $3 \%$ of all patients.. The median age of SARI cases was 41(30-60) years compared to 35 (19-54) years for ILI cases,. Patients with SARI compared to patients with ILI were more likely to be elderly patients aged $\geq 65$ years $(20 \%$ vs $12 \%, \mathrm{p}<0.001)$ and patients with comorbidity ( $36 \%$ vs $8 \%, p<0.001)$. In contrast, patients with ILI were more likely to be from children $<15$ years $(22 \%$ vs $13 \%, \mathrm{p}=0.004)$.

Table 1 shows patient's characteristics with influenzalike illness and severe acute respiratory infection during 2018/2019 season in Yemen.

\section{Influenza positivity rate}

Influenza viruses were detected in 411 samples out of 768 tested samples that give an overall 53.5\% influenza positivity rate, $59 \%(167 / 284)$ in SARI patients and $50 \%$ $(244 / 484)$ in ILI patients. Out of 411 positive samples, $280(68 \%)$ were influenza A subtype (H1N1) pdm09, $110(27 \%)$ were influenza B and 21 (5\%) were influenza

Table 1 Characteristics of patients with influenza-like illness and severe acute respiratory infection during 2018/2019 season in Yemen

\begin{tabular}{|c|c|c|c|c|c|c|c|}
\hline & \multicolumn{2}{|l|}{ All case } & \multicolumn{2}{|c|}{ SARI cases } & \multicolumn{2}{|l|}{ ILI cases } & \multirow[t]{2}{*}{$\mathrm{p}$ value } \\
\hline & $N=768$ & Percent (\%) & $N=284$ & Percent 37 (\%) & $N=484$ & Percent 63 (\%) & \\
\hline \multicolumn{8}{|l|}{ Age } \\
\hline$<15$ & 143 & 19 & 38 & 13 & 105 & 22 & 0.004 \\
\hline $15-<25$ & 56 & 7 & 19 & 7 & 37 & 8 & Ref \\
\hline $25-<35$ & 118 & 15 & 38 & 13 & 80 & 17 & 0.821 \\
\hline $35-<45$ & 141 & 18 & 54 & 19 & 87 & 18 & 0.567 \\
\hline $45-<55$ & 110 & 14 & 50 & 18 & 60 & 12 & 0.156 \\
\hline $55-<65$ & 83 & 11 & 27 & 10 & 56 & 12 & 0.864 \\
\hline$\geq 65$ & 117 & 15 & 58 & 20 & 59 & 12 & 0.303 \\
\hline \multicolumn{8}{|l|}{ Sex } \\
\hline M & 531 & 69 & 195 & 69 & 336 & 69 & 0.825 \\
\hline $\mathrm{F}$ & 237 & 31 & 89 & 31 & 148 & 31 & \\
\hline \multicolumn{8}{|l|}{ Co morbidity } \\
\hline Yes & 142 & 18 & 102 & 36 & 40 & 8 & $<0.001$ \\
\hline \multicolumn{8}{|l|}{ Diabetes } \\
\hline Yes & 80 & 10 & 61 & 21 & 19 & 4 & $<0.001$ \\
\hline No & 688 & 90 & 223 & 79 & 465 & 96 & \\
\hline \multicolumn{8}{|l|}{ Hypertension } \\
\hline Yes & 38 & 5 & 32 & 11 & 6 & 1 & $<0.001$ \\
\hline No & 730 & 95 & 252 & 89 & 478 & 99 & \\
\hline \multicolumn{8}{|l|}{ Heart disease } \\
\hline Yes & 44 & 6 & 36 & 13 & 8 & 2 & $<0.001$ \\
\hline No & 724 & 94 & 248 & 87 & 476 & 98 & \\
\hline Renal diseases & & 0 & & & & & \\
\hline Yes & 49 & 6 & 31 & 11 & 18 & 4 & $<0.001$ \\
\hline No & 719 & 94 & 253 & 89 & 466 & 96 & \\
\hline \multicolumn{8}{|l|}{ Respiratory } \\
\hline Yes & 23 & 3 & 18 & 6 & 5 & 1 & $<0.001$ \\
\hline No & 745 & 97 & 266 & 94 & 479 & 99 & \\
\hline
\end{tabular}


A not subtyped. The overall positivity of influenza was significantly higher among SARI patients compared to ILI patients (59\% vs $50 \%, \mathrm{p}=0.041)$. It also was significantly higher among SARI than ILI patients in children $<15$ years $(95 \%$ vs, $66 \%, \mathrm{p}<0.001)$, age group $45-<55$ years $(60 \%$ vs. $37 \%, \mathrm{p}=0.014)$ and elderly patients aged $\geq 65$ years $(83 \%$ vs. $56 \%, p<0.002)$. For other age groups, e.g. $15-<45$ years, slightly higher positivity among ILI patients than SARI, but no statistical difference between the two groups.

Figure 1 shows influenza positivity rate among patients with influenza-like illness (ILI) and severe acute respiratory infection (SARI), by age group, 2018-2019 season, Yemen.

From the overall 53.5\% influenza positive cases, 39\% (301) were confirmed with influenza A and 14\% (110) with $B$. The highest positivity rate of influenza $A$ was $44 \%$ among $\geq 65$ years with slight fluctuation in other age groups. The highest positivity rate for influenza B was $33 \%$ among $<15$ years old.

Figure 2 shows positivity of influenza type A and B among patients with influenza-like illness (ILI) and severe acute respiratory infection (SARI), by age group, 2018-2019 season, Yemen.

\section{Risk factors for hospitalizing influenza-associated SARI}

From 411 patients with positive influenza result, 167 (41\%) SARI patients and 244 (59\%) ILI patients were included in univarate and multivariate analysis. The significant associated risk factors considered in univariate analysis were age between 45 and $<65$ (OR 2.4) and $\geq 65$ years (OR 4.0) compared with $5-<25$ years, diabetes $(\mathrm{OR}=7.0)$, hypertension $(\mathrm{OR}=7.3)$, chronic heart disease $(\mathrm{OR}=7.3)$, chronic renal diseases
$(\mathrm{OR}=2.9)$ and chronic respiratory diseases $(\mathrm{OR}=6.2)$. The risk factors that remained independently associated with influenza-associated SARI in multivariate analysis were ages $<5$ years (OR 2.8, 95\% CI 1.2-6.8, $\mathrm{p}=0.026$ ), $\geq 65$ years (OR 3.1, CI 1.2-7.8, $\mathrm{p}=0.016$ ) compared to $5-<25$ years old. Also diabetes (OR 4.7, 95\% CL: 2.3-9.5, p<0.001), heart diseases (OR 3.1, 95\% CI 1.3-15.0, $\mathrm{p}=0.018$ ) and chronic respiratory disease (OR 5.0, 95\% CI 1.2-19.9, $\mathrm{p}=0.021$ ).

Table 2 shows univariate and multivariate analysis for influenza associated SARI during 2018/2019 season, Yemen.

\section{Discussion}

In this study, we analyzed influenza surveillance data to provide insight into influenza positivity, type of influenza viruses and risk factors for influenza-associated hospitalization in the crisis country, Yemen.

Our finding showed high positivity rate for influenza among both SARI and ILI patients. This result might be due to the time of infection, which occurred during winter months when the transmission of human influenza usually reaches the highest peaks [20-24]. This result was within the range of reported influenza positivity during 2018/2019 season form Western Asia where our country is located [24].

Furthermore influenza type A and subtype A (H1N1) pdm09 were the predominant circulating viruses. This result was consistent with the result reported from some countries in Western Asia (Kuwait and Qatar) and other countries form Middle East and North Africa region during the previous two seasons $2017 / 2018$ and 2018/2019 $[20,23-26]$

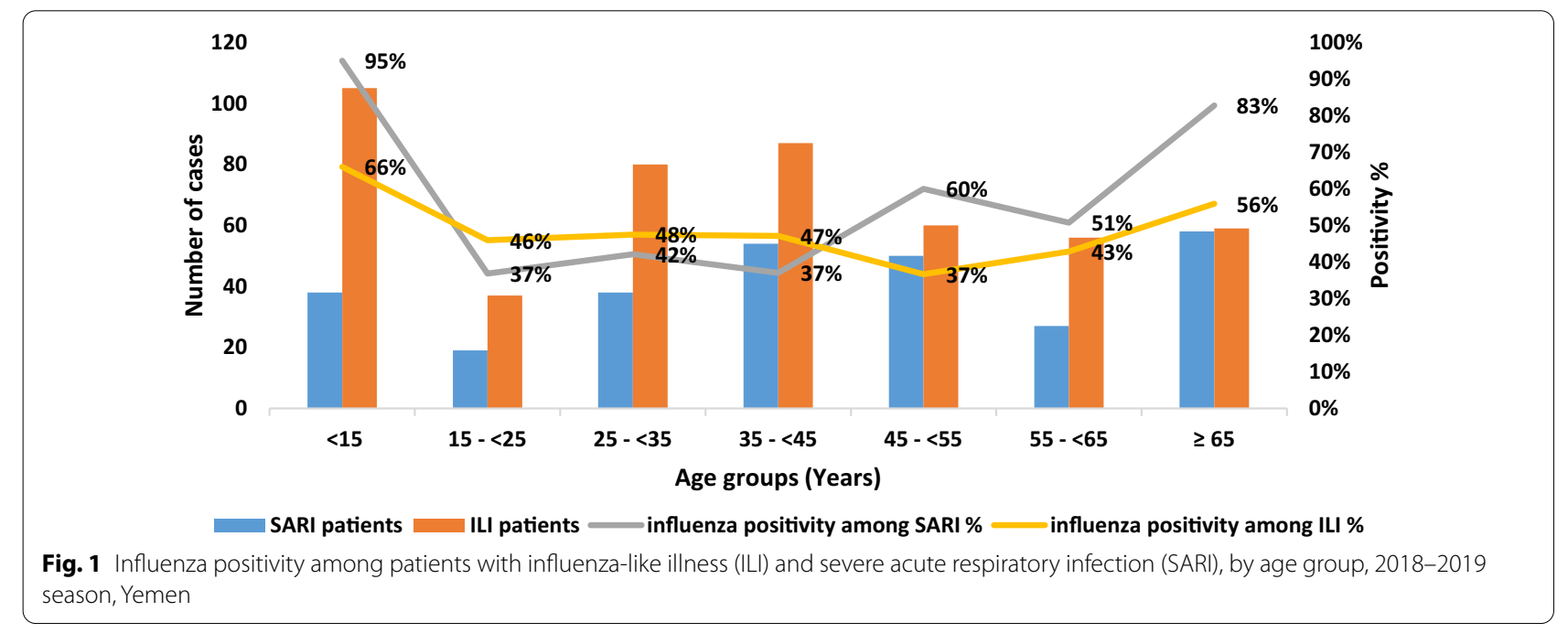




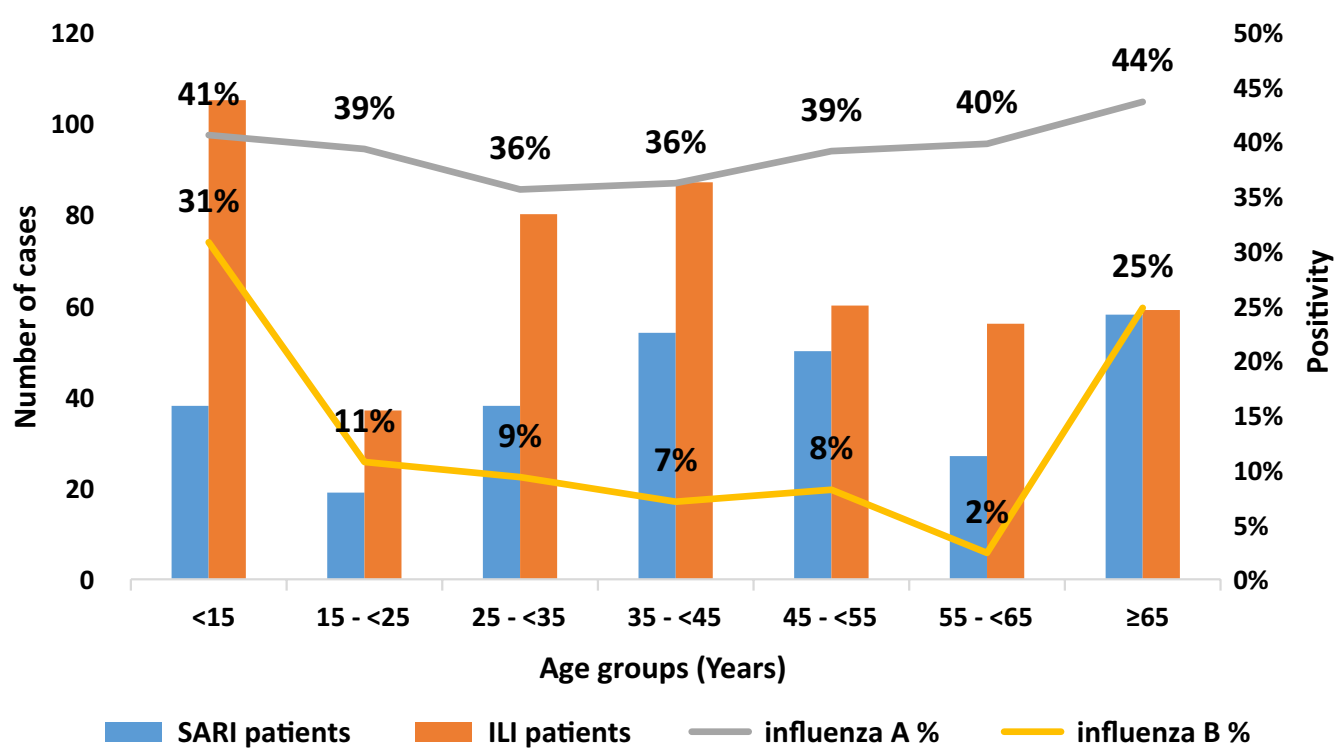

Fig. 2 Positivity of influenza type A and B among patients with influenza-like illness (ILI) and severe acute respiratory infection (SARI), by age group, 2018-2019 season, Yemen

Table 2 Univariate and Multivariate Analysis for Influenza Associated Severe Acute Respiratory Illness, 2018/2019 Season, Yemen

\begin{tabular}{|c|c|c|c|c|c|c|}
\hline \multirow[t]{2}{*}{ Variables } & \multirow{2}{*}{$\begin{array}{l}\text { Influenza } \\
\text { Associated SARI } \\
167\end{array}$} & \multirow{2}{*}{$\begin{array}{l}\text { influenza } \\
\text { Associated ILI } \\
244\end{array}$} & \multicolumn{2}{|l|}{ Univariate analysis } & \multicolumn{2}{|l|}{ Multivariate analysis } \\
\hline & & & Odds ratio $(95 \% \mathrm{CI})$ & $P$ value & Odds ratio $(95 \% \mathrm{Cl})$ & $P$ value \\
\hline \multicolumn{7}{|l|}{ Age } \\
\hline$<5$ & $33 / 167(20)$ & 48/244 (20) & $2.2(0.9-4.9)$ & 0.058 & $2.8(1.2-6.8)$ & $0.026^{\mathrm{a}}$ \\
\hline $5-<25$ & $11 / 167(7)$ & $35 / 244(14)$ & Ref & & Ref & \\
\hline $25-<45$ & $37 / 167(22)$ & 79/244 (32) & $1.5(0.7-3.2)$ & 0.317 & $1.9(0.8-4.5)$ & 0.124 \\
\hline $45-<65$ & $41 / 167(25)$ & 46/244 (19) & $2.4(1.3-6.3)$ & $0.010^{\mathrm{a}}$ & $2.3(0.9-5.7)$ & 0.052 \\
\hline$\geq 65$ & 45/167 (27) & $36 / 244(15)$ & $4.0(1.8-9.0$ & $0.001^{\mathrm{a}}$ & $3.1(1.2-7.8)$ & $0.016^{\mathrm{a}}$ \\
\hline Diabetes & $50 / 167(30)$ & $14 / 244(6)$ & $7.0(3.7-13.2)$ & $<0.001^{\mathrm{a}}$ & $4.7(2.3-9.5)$ & $<0.001^{\mathrm{a}}$ \\
\hline Hypertension & 26/167 (16) & 6/244(2) & $7.3(2.9-18.2)$ & $<0.001^{\mathrm{a}}$ & $1.2(0.3-4.1)$ & 0.790 \\
\hline Heart disease & $26 / 167(16)$ & $6 / 244(2)$ & $7.3(2.9-18.2)$ & $<0.001^{\mathrm{a}}$ & $3.1(1.3-15.0)$ & $0.018^{\mathrm{a}}$ \\
\hline Renal diseases & 24/167 (14) & $13 / 244(5)$ & $2.9(1,8-6.0)$ & $0.001^{\mathrm{a}}$ & $1.8(0.7-4.1)$ & 0.214 \\
\hline Respiratory & $12 / 167(7)$ & $3 / 244(1)$ & $6.2(1.7-22.7)$ & $0.001^{\mathrm{a}}$ & $5.0(1.2-19.9)$ & $0.021^{\mathrm{a}}$ \\
\hline
\end{tabular}

${ }^{a}$ Statistically Significant, SARI, severe acute respiratory infection. ILI, influenza like illness

An increase in number of SARI cases corresponded to the peaks of influenza activity during 2018/2019 season has been reported in neighboring countries: Saudi Arabia and Oman [24]. This was consistent with our result that showed higher positivity in SARI patients.

Out study showed varied positivity rate for influenza in SARI and ILI patients, higher positivity in children $<15$ years and patient's $\geq 65$ years compared to other age groups within both SARI and ILI patient. Higher positivity in patients with SARI compared to those with ILI except for age group $\geq 15$ to $<45$ years old.
This variation has been demonstrated in many studies with some differences; study in Morocco showed highest positivity rates among $\geq 65$ years of SARI patients compared to 5-15 years of ILI patients [25]. Study conducted in Egypt reported similar positivity among $<15$ years, increase in the positivity in SARI and decrease in ILI patients $\geq 15$ years old [27]. Other study in China revealed similar activity of influenza virus among patients $<5$ years with ILI and SARI [28].

The difference might be due to the different in the size and age distribution of population under study. Equal 
proportion for age groups in our study with higher ages compared to large population and predominates of children $<15$ years in those studies.

However, influenza B viruses were not predominant in our results and it was similar to the countries of Western Asia where our country is located [24]. Our study showed different positivity rates of influenza B in different age groups, the highest positivity was among children $<15$ years, followed by patients $\geq 65$ years old.

The higher positivity rate among $\geq 65$ years was consistent with a study conducted in Egypt which revealed that influenza $B$ was more common in patients aged $\geq 65$ years [27]. The highest positivity rate in children might be due to the fact that even influenza $B$ affects all age groups, children play as vectors for the spread of virus and schoolchildren are more infected $[29,30]$.

Out findings showed high detection rate among SARI patients $59 \%$ compared to $(5 \%-10.9 \%)$ of previous studies conducted in Yemen during period 2011-2016 [6-8, 31, 32]. This might be due to that SARI patients in previous studies were from whole year, while patients of our study were from winter months. This result was consistent with previous study which demonstrated $23 \%$ detection rate for influenza from SARI patients during winter season compared to $2 \%$ during the rest 3 seasons of the year ( $p$ value $<0.001)$ [6].

The multivariate analysis of this study identified risk factors for hospitalization of severe influenza-associated SARI including extremes age $<5$ and $\geq 65$ years and three comorbidities: diabetes, heart disease and chronic respiratory disease. These risk factors have been founded in several studies conducted in developing and developed countries [25, 33-35]. As well as, they were within the risk group to whom WHO recommended influenza vaccination [17].

The risk of chronic renal disease is certainly the subject of a confounding effect due to the statistical association with the diabetes and heart disease.

In contest to result of study conducted in Morocco, males were found to be not associated with hospitalization of influenza associated-SARI. This might be due to equal proportion of patients according to sex in our study compared to the over-recruitment of women in that study.

There are some limitations in this study. It is based on secondary data collected from ten governorates patients co-morbidities included only the most common chronic disease in Yemen. The risk of other co morbidities such as HIV, malnourished people and pregnancy were not studied because either this information was not available in the data or the low prevalence such as HIV. Furthermore, the results for influenza B subtype and other respiratory viruses such as Respiratory Syncytial Virus were not available due to the shortage of laboratory kits. As well as bacterial etiology such as Streptococcus pneumoniae, Haemophilus influenzae, and Staphylococcus aureus that contributed in hospitalization of SARI [2] were not available.

Nevertheless, the current study provides information about influenza positivity and risk factors for hospitalization of influenza associated SARI in Yemen, particularly in cold climate governorates. It could help public health authorities to introduce influenza vaccine for people at high risk particular under 5 years and elderly people, diabetics, patients with cardiac diseases and respiratory diseases.

\section{Conclusion}

The positivity rate for influenza during 2018/2019 season was high in cold climate governorates of Yemen. The positivity rate for influenza viruses among patients with SARI and ILI varied according to age distribution. Influenza Type A virus and subtype AH1N1 were predominant circulating viruses and co circulated with influenza type B. Influenza type A virus was higher among elderly SARI patients, while influenza type $B$ virus was higher among $<15$ years old. Extremes age $<5$ and $\geq 65$ years, underlying conditions including diabetes, cardiac diseases, chronic respiratory diseases were the identified risk factors for hospitalization of influenza associated SARI. Introducing influenza vaccine for these risk groups is highly recommended. A prospective study to assess co morbidities as risk factors for influenza associated SARI should be conducted. Strengthening laboratory capacity to detect other respiratory pathogens is highly recommended.

\section{Abbreviations \\ AOR: Adjusted Odds Ratio; Cl: Confidence Interval; eDEWS: Electronic disease early warning system; ILI: Influenza like illness; NCPH: National Central public Health Laboratory; OR: Odds Ratio; RT-PCR: Reverse transcription polymerase Chain Reaction; SARI: Severe acute respiratory infection; WHO: World health Organization.}

\section{Acknowledgements \\ Not applicable.}

\section{Authors' contributions}

MA and KA contributed to conception and design of the study. MA performed the statistical analysis, wrote the draft manuscript. KA organized the data, involved in statistical analysis. Both authors read and approved the final manuscript.

\section{Funding}

The authors declare that the research was conducted in the absence of any commercial or financial relationships that could be construed as a potential conflict of interest.

\section{Availability of data and materials}

All relevant data are presented in this paper; and more information can be provided upon reasonable request from the correspondence author. 


\section{Declarations}

\section{Ethics approval and consent to participate}

As these data were secondary data, collected by surveillance staff, obtained from the influenza surveillance system and the use of such data is part of the national surveillance activities, the study did not require formal ethical review. An official permission to perform this study was obtained from Ministry of Public Health and Population. I confirm that all methods were performed in accordance with the relevant guidelines and regulations in the county. The study did not involve experiments on human subject or human participants under the age of 18 years. No human studies are presented in this manuscript.

\section{Consent for publication}

This study does not include any identifiable human images or data and thus does not require a consent to publish.

\section{Competing interests}

The authors declare that they have no competing interests.

\section{Author details}

${ }^{1}$ Yemen Field Epidemiology Training Program, Sana'a, Yemen. ${ }^{2}$ Ministry of Public Health and Population, Sana'a, Yemen.

Received: 28 April 2021 Accepted: 20 January 2022

Published online: 01 February 2022

\section{References}

1. Influenza (Seasonal). https://www.who.int/news-room/fact-sheets/detail/ influenza-(seasonal)

2. Gordon A, Reingold A. The burden of influenza: a complex problem. Curr Epidemiol Rep. 2018:5(1):1-9.

3. Jia L, Xie J, Zhao J, Cao D, Liang Y, Hou X, Wang L, Li Z. Mechanisms of severe mortality-associated bacterial co-infections following influenza virus infection. Front Cell Infect Microbiol. 2017;7:338.

4. Manohar P, Loh B, Nachimuthu R, Hua X, Welburn SC, Leptihn S. Secondary bacterial infections in patients with viral pneumonia. Front Med. 2020;7:420.

5. Bellos A, Mulholland K, O'Brien KL, Qazi SA, Gayer M, Checchi F. The burden of acute respiratory infections in crisis-affected populations: a systematic review. Confl Heal. 2010:4:3.

6. Jaadan BM, Al-Shamahy HA, Al-Harazi AH, Al-Ademi DAA: Detection of Influenza Viruses among Hospitalized Cases Suffering from Severe Acute Respiratory Illness (Sari) in Sana'a City, Yemen. Univ J Pharm Res. 2019.

7. Al Amad MA, Al Mahagri AA, Al Serouri AA, Khader YS. Severe acute respiratory infections with influenza and noninfluenza respiratory viruses: Yemen, 2011-2016. Inquiry. 2019;56:46958019850731

8. Thabet AA, Al-Kohani A, Shadoul A, Al-Mahaqri A, Bin Yahya M, Saleh AH, Al-Adeemy D, Khan W, Malik M. Characteristics of severe acute respiratory infectionassociated hospitalization in Yemen, 2014/15. East Mediterr Health J. 2016;22(7):440-4.

9. Mayad M, Alyusfi R, Assabri A, Khader Y. An electronic disease early warning system in Sana'a governorate, Yemen: evaluation study. JMIR Public Health Surveill. 2019;5(4):e14295.

10. Dureab F, Ahmed K, Beiersmann C, Standley CJ, Alwaleedi A, Jahn A Assessment of electronic disease early warning system for improved disease surveillance and outbreak response in Yemen. BMC Public Health. 2020;20(1):1422

11. Dureab F. The usefulness of the electronic Disease Early Warning System (eDEWS) in the humanitarian crisis of Yemen. 2020

12. Luyt CE, Rice TW. Co-infection in severe influenza: a new epidemiology? Intensive Care Med. 2017;43(1):107-9.

13. Sf MSF. Health system in Yemen close to collapse. Bull World Health Organ. 2015;93:670-1.

14. Zawiah M, Al-Ashwal FY, Saeed RM, Kubas M, Saeed S, Khan AH, Sulaiman SAS, Abduljabbar R. Assessment of healthcare system capabilities and preparedness in Yemen to confront the novel coronavirus 2019 (COVID19) outbreak: a perspective of healthcare workers. Front Public Health. 2020;8(419):419.
15. El Bcheraoui C, Jumaan AO Collison ML Daoud F Mokdad AH. Health in Yemen: losing ground in war time. Glob Health. 2018;14(1):42.

16. Al Amad MA AMA: Influenza epidemic with high mortality during the winter months in Yemen, 2018-2019. Oman Med J. 2020, 35(1)

17. World Health Organization: WHO Strategic Advisory Group of Experts on immunization: request for nominations. Weekly Epidemiological Record Relevé épidémiologique hebdomadaire. 2009, 84(15):131-132.

18. Global epidemiological surveillance standards for influenza.

19. Fitzner J, Qasmieh S, Mounts AW, Alexander B, Besselaar T, Briand S, Brown C, Clark S, Dueger E, Gross D, et al. Revision of clinical case definitions: influenza-like illness and severe acute respiratory infection. Bull World Health Organ. 2018;96(2):122-8.

20. Elhakim M, Hafiz Rasooly M, Fahim M, Sheikh Ali S, Haddad N, Cherkaoui I, Hjaija D, Nadeem S, Assiri A, Aljifri A, et al. Epidemiology of severe cases of influenza and other acute respiratory infections in the Eastern Mediterranean Region, July 2016 to June 2018. J Infect Public Health. 2020;13(3):423-9.

21. Malik M, Mahjour J, Khan W, Alwan A. Influenza in the Eastern Mediterranean Region: identifying the unknowns for detection and control of epidemic and pandemic threats. EMHJ. 2016;22(7):428-9.

22. Khan W, El Rifay AS, Malik M, Kayali G. Influenza research in the Eastern Mediterranean region: a review. Oman Med J. 2017;32(5):359-64.

23. Caini S, El-Guerche Seblain C, Ciblak MA, Paget J. Epidemiology of seasonal influenza in the Middle East and North Africa regions, 2010-2016: circulating influenza A and B viruses and spatial timing of epidemics. Influenza Other Respir Viruses. 2018;12(3):344-52

24. Hammond A, Hundal K, Laurenson-Schafer H, Cozza V, Maharjan B, Fitzner J, Samaan M, Vandemaele K, Zhang W. Review of the 2018-2019 influenza season in the northern hemisphere. Wkly Epidemiol Rec. 2019;94(32):345-65

25. Ezzine $\mathrm{H}$, Cherkaoui I, Rguig A, Oumzil H, Mrabet M, Bimouhen A, Falaki FE, Regragui Z, Tarhda Z, Youbi M, et al. Influenza epidemiology and risk factors for severe acute respiratory infection in Morocco during the 2016/2017 and 2017/2018 seasons. Pan Afr Med J. 2020;36:159.

26. Hammond A, Laurenson-Schafer $\mathrm{H}$, Marsland M, Besselaar T, Fitzner J, Vandemaele K, Zhang W. Review of the 2017-2018 influenza season in the northern hemisphere/Bilan de la saison grippale 2017-2018 dans I'hemisphere Nord. Wkly Epidemiol Rec. 2018:93(34):429-45.

27. Refaey S, Amin M, Labib M, Kandeel A. Influenza virus positivity and circulating subtypes among cases of influenza-like illness and severe acute respiratory infection, Egypt, 2012-2015. EMHJ. 2016;22(7):523-32.

28. Cheng W, Yu Z, Liu S, Zhang X, Wang X, Cai J, Ling F, Chen E. Comparison of influenza epidemiological and virological characteristics between outpatients and inpatients in Zhejiang Province, China, March 2011-June 2015. Int J Environ Res Public Health. 2017;14(2):217.

29. Caini S, Huang QS, Ciblak MA, Kusznierz G, Owen R, Wangchuk S, Henriques CM, Njouom R, Fasce RA, Yu H, et al. Epidemiological and virological characteristics of influenza B: results of the Global Influenza B Study. Influenza other Resp Viruses. 2015:9(Suppl 1):3-12.

30. Oh YN, Kim S, Choi YB, Woo SI, Hahn YS, Lee JK. Clinical similarities between influenza A and B in children: a single-center study, 2017/18 season, Korea. BMC Pediatr. 2019;19(1):472.

31. Ahmed AKT, Najeeb MM, Abdulhakeem A-K, Mohammed J. Epidemiology of fatal cases associated with pandemic influenza reported in Yemen. Nat Sci. 2012, 2012

32. Al Amad M, Al Mahqri A, Al Serouri A. Severe acute respiratory infections associated with influenza and non-influenza viruses-Yemen, 2011-2014. Int J Infect Dis. 2016:45:291.

33. Tempia S, Walaza S, Moyes J, Cohen AL, von Mollendorf C, Treurnicht FK, Venter M, Pretorius M, Hellferscee O, Mtshali S, et al. Risk factors for influenzaassociated severe acute respiratory illness hospitalization in South Africa 2012-2015. Open Forum Infect Dis. 2017:4(1):ofw262.

34. Zhang Y, Muscatello DJ, Wang Q, Yang P, Pan Y, Huo D, Liu Z, Zhao X, Tang Y, Li C, et al. Hospitalizations for influenza-associated severe acute respiratory infection, Beijing, China, 2014-2016. Emerg Infect Dis. 2018;24(11):2098-102.

35. Cummings MJ, Bakamutumaho B, Kayiwa J, Byaruhanga T, Owor N, Namagambo B, Wolf A, Wamala JF, Morse SS, Lutwama JJ, et al. Epidemiologic and spatiotemporal characterization of influenza and severe acute respiratory infection in Uganda, 2010-2015. Ann Am Thorac Soc. 2016:13(12):2159-68. 


\section{Publisher's Note}

Springer Nature remains neutral with regard to jurisdictional claims in published maps and institutional affiliations.

- fast, convenient online submission

- thorough peer review by experienced researchers in your field

- rapid publication on acceptance

- support for research data, including large and complex data types

- gold Open Access which fosters wider collaboration and increased citations

- maximum visibility for your research: over $100 \mathrm{M}$ website views per year

At BMC, research is always in progress.

Learn more biomedcentral.com/submissions 